\section{All Reads}
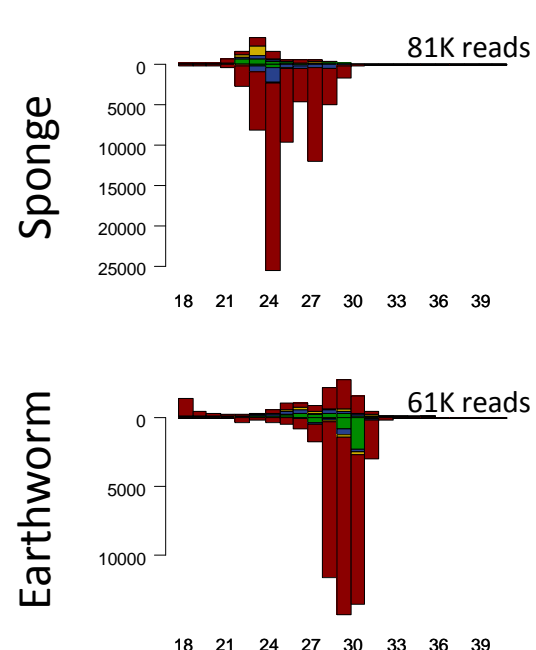

$\begin{array}{llllllll}18 & 21 & 24 & 27 & 30 & 33 & 36 & 39\end{array}$

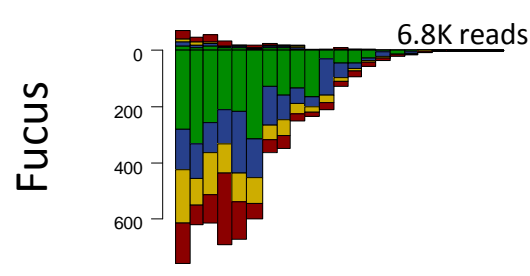

$\begin{array}{llllllll}18 & 21 & 24 & 27 & 30 & 33 & 36 & 39\end{array}$

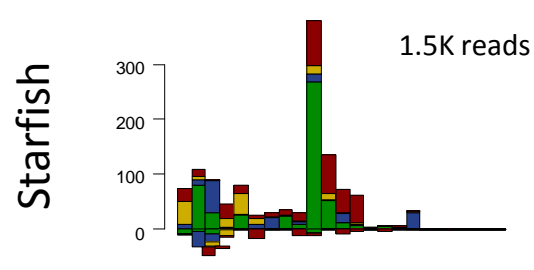

$\begin{array}{llllllll}18 & 21 & 24 & 27 & 30 & 33 & 36 & 39\end{array}$

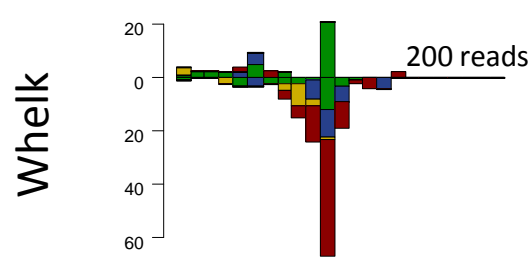

$\begin{array}{llllllll}18 & 21 & 24 & 27 & 30 & 33 & 36 & 39\end{array}$

\section{Most mapped contig}
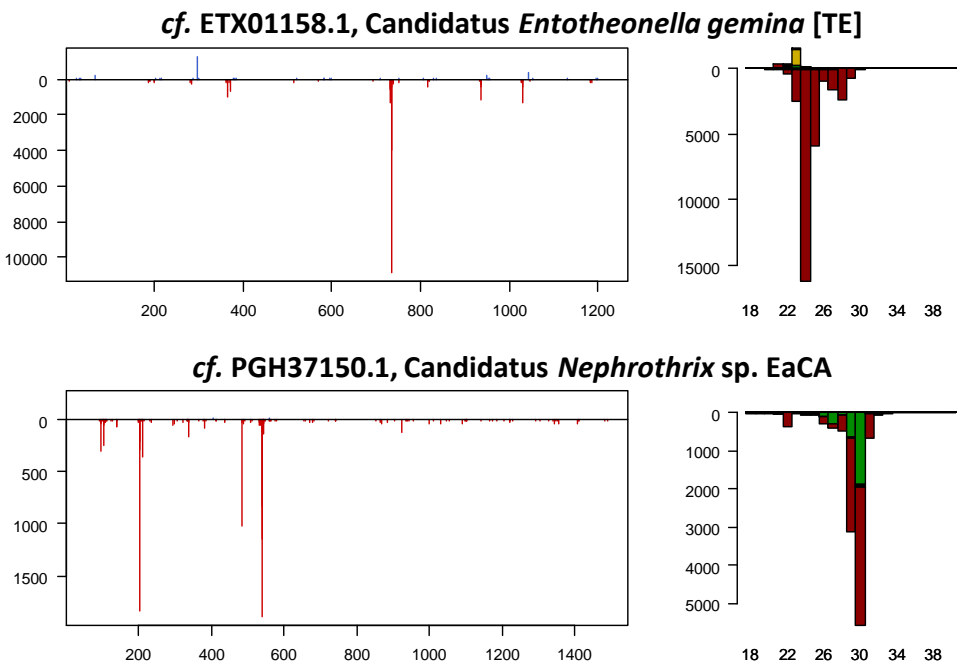

cf. Sphingobacteria rRNA
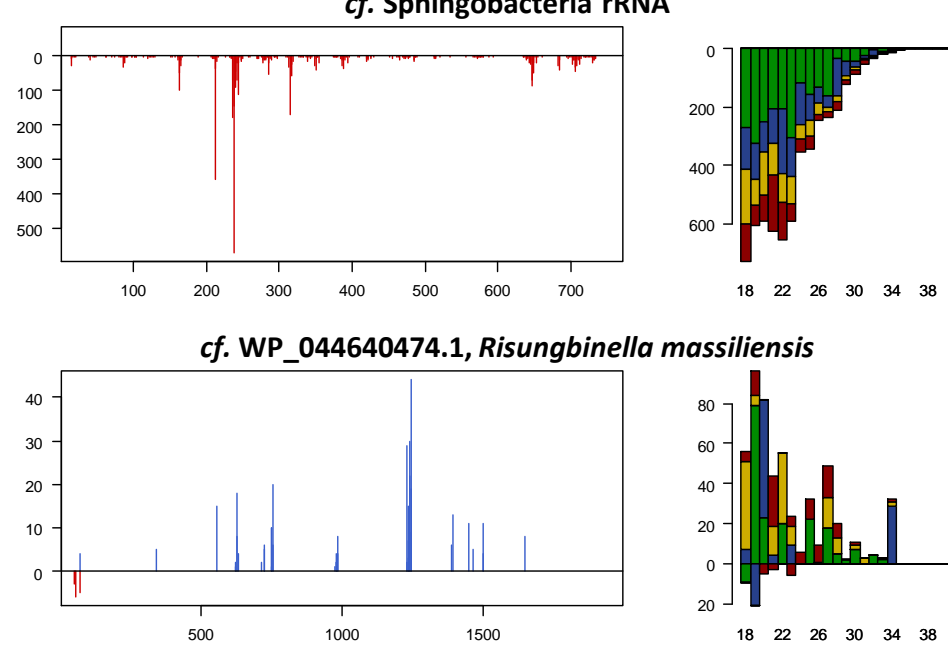

cf. PVD34672.1, Pomacea canaliculata [TE]
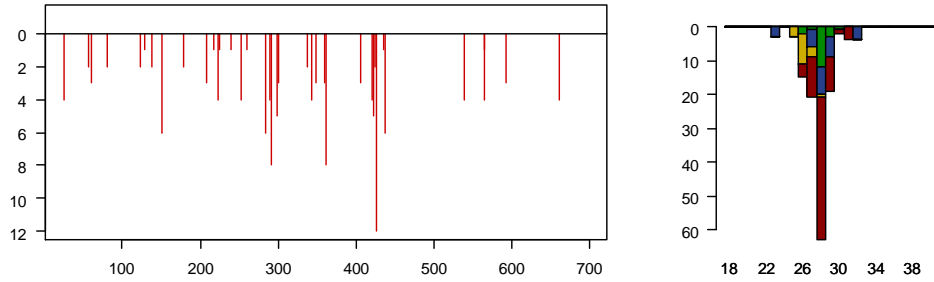

\section{Second most mapped contig}

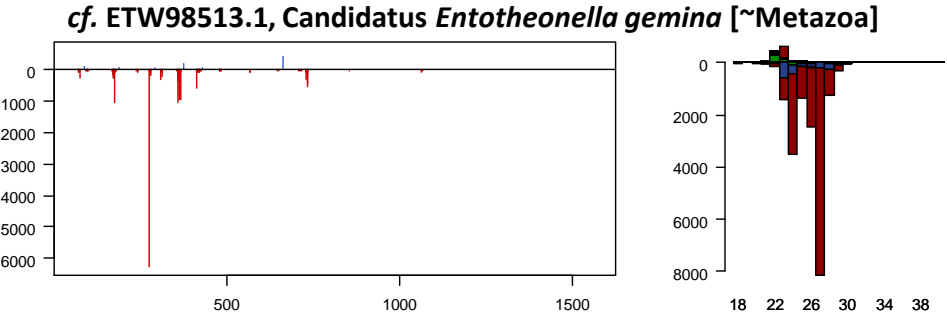

cf. PGH39643.1, Candidatus Nephrothrix sp. EaCA [TE]
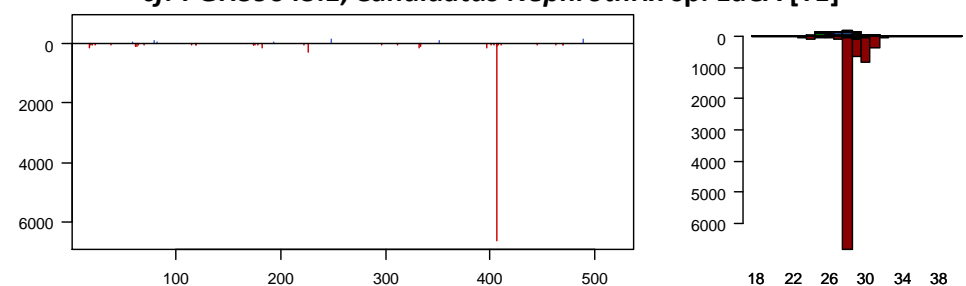

cf. chloroplast psbA
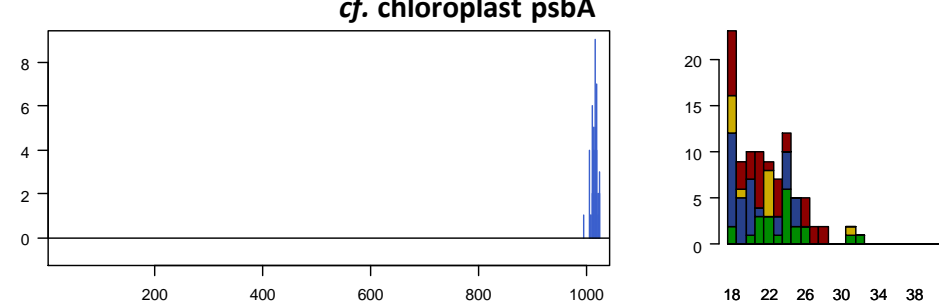

$\begin{array}{llllll}18 & 22 & 26 & 30 & 34 & 38\end{array}$
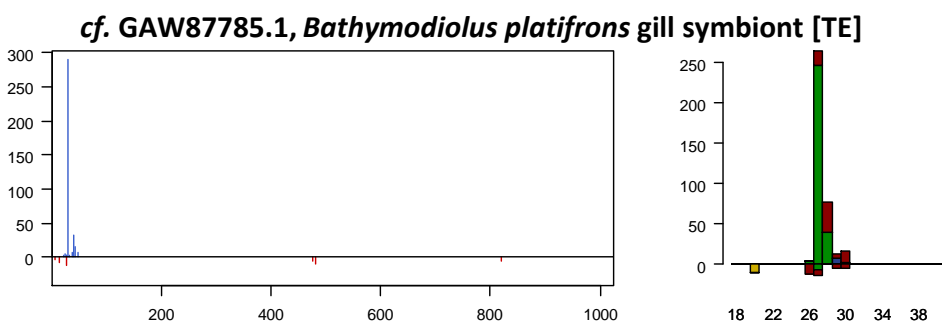

cf. PVD34672.1, Pomacea canaliculata [TE]

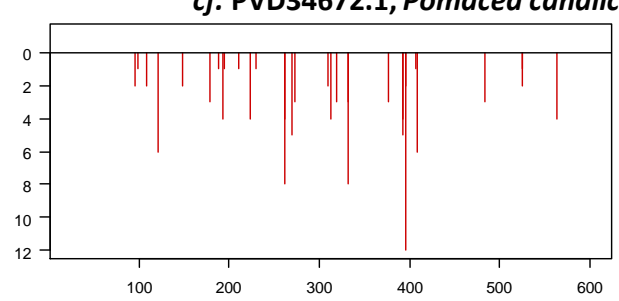

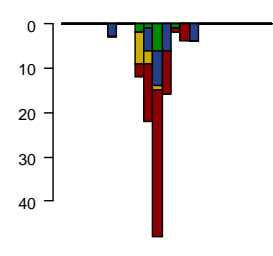

